\title{
eCommons@AKU
}

Department of Obstetrics \& Gynaecology

Division of Woman and Child Health

March 2018

\section{Uterine arteriovenous malformations after suction evacuation of missed miscarriage}

\author{
Arshia Javed \\ Aga Khan University, arshia.javed@aku.edu \\ Reeta Chander \\ Aga Khan University \\ Zahra Hoodbhoy \\ Aga Khan University, zahra.hoodbhoy@aku.edu
}

Follow this and additional works at: https://ecommons.aku.edu/ pakistan_fhs_mc_women_childhealth_obstet_gynaecol

Part of the Maternal and Child Health Commons, Obstetrics and Gynecology Commons, and the Women's Health Commons

\section{Recommended Citation}

Javed, A., Chander, R., Hoodbhoy, Z. (2018). Uterine arteriovenous malformations after suction evacuation of missed miscarriage. Journal of the College of Physicians and Surgeons--Pakistan : JCPSP, 28(3), S33-S34.

Available at: https://ecommons.aku.edu/pakistan_fhs_mc_women_childhealth_obstet_gynaecol/89 


\title{
Uterine Arteriovenous Malformations after Suction Evacuation of Missed Miscarriage
}

\author{
Arshia Javed1', Reeta Chander ${ }^{1}$ and Zahra Hoodbhoy²
}

\begin{abstract}
Uterine arteriovenous malformation (AVM) is an uncommon but life-threating source of bleeding. AVM is an abnormal connection between uterine arteries and veins. Patients typically present with vaginal bleeding following miscarriage (medical/surgical) or cesarean section. The treatment of choice depends on the symptoms, age, desire of fertility, localization and size of the lesion. Uterine artery embolization is the first choice in symptomatic patients of reproductive age group. We report a case of AVM presenting after dilation and evacuation with extensive lesion, which was successfully treated with bilateral uterine artery embolization.
\end{abstract}

Key Words: Vaginal bleeding. Arteriovenous malformation. Uterine artery embolization.

\section{INTRODUCTION}

Uterine arteriovenous malformation (AVM) is an uncommon but a life-threating condition, due to profuse or irregular bleeding from abnormal connection between artery and vein. ${ }^{1}$ The incidence or prevalence of AVM is unknown. Only 100 cases have been reported since 1926.2 The few available case reports reflect the rare nature of uterine AVM. AVM is uncommon in nulliparous women and has been reported in patient with age group ranging from 18-72 years. ${ }^{3}$ The lesion can be congenital or acquired. Congenital AVMs are rare and arise from anomalous differentiation of primitive capillary plexus which results in abnormal connections between arteries and veins. ${ }^{2}$ Acquired AVMs are caused by uterine trauma and instrumentation, such as, in dilatation and curettage, therapeutic miscarriage, trophoblastic disease, cesarean section, endometriosis or endometrial cancers. ${ }^{2}$ Angiography has been proved as gold standard test for the diagnosis of AVM. ${ }^{3}$ Recently, color Doppler ultrasound has been used for obtaining a reliable diagnosis. It showed reversal of flow and colour mosaic pattern. ${ }^{4}$

We report a case of AVM after dilatation and curettage in a primigravida which was successfully treated with bilateral uterine artery embolization.

\section{CASE REPORT}

A 21-year primipara was admitted through clinic with complain of heavy vaginal bleeding for the past two

I Department of Obstetrics and Gynecology, The Aga Khan Hospital for Women, Garden, Karachi.

2 Department of Obstetrics and Gynecology, The Aga Khan University Hospital, Karachi.

Correspondence: Dr. Arshia Javed, Senior Instructor, Obstetrics and Gynecology, The Aga Khan Hospital for Women, Garden, Karachi.

E-mail: drarshiajaved@yahoo.com

Received: August 03, 2017; Accepted: November 01, 2017. days. She had uterine curettage 7 weeks back due to missed miscarriage at 8 weeks of gestation. Over previous few weeks, she reported on-and-off vaginal bleeding episodes, for which, she visited clinic twice. Medical treatment, antifibrinolytic agents, and oral progesterone were given but she did not respond to treatment. Hence, she was advised admission for workup and further management. On admission, her general examination was normal except pale appearance. The pelvic examination showed no active vaginal bleeding, slightly enlarged uterus and no adnexal abnormality.

Laboratory evaluation revealed a hemoglobin of $7.9 \mathrm{~g} / \mathrm{dl}$ with hematocrit (Hct) $25.3 \%$ and normal platelet counts of $351 \times 109 / \mathrm{L}$. Her serum beta human chorionic gonadotropin $(\beta \mathrm{HCG}$ ) level was $2.7 \mathrm{miu} / \mathrm{ml}$, which confirmed that she was non-pregnant. Transvaginal scan at the time of admission revealed the endometrial canal widened with heterogeneous debris and multiple cystic spaces with marked vascularity.

Doppler ultrasonography on the following day showed a highly vascular anterior uterine wall. The endometriomyometrial interface was lost due to AVM (Figure 1). The patient was referred for consultation with an interventional radiologist and uterine artery embolization was planned and done on the same day. Two packs of blood were transfused before procedure. Bilateral uterine artery embolization was done with (355-500 um) polyvinyl alcohol (PVA) particles. The pre- and postembolization images of patient are shown in (Figure 2). No post-procedural complication occurred. Patient was hemodynamically stable with slight spotting after the procedure.

The patient was discharged two days after the procedure. She returned for her follow-up on the 10th postoperative day when she had no symptoms and was vitally stable. 


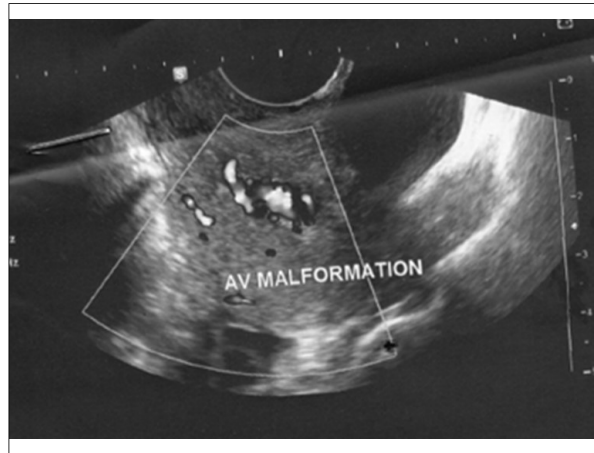

Figure 1: Colored Doppler ultrasound imaging feature of uterine arteriovenous malformation.

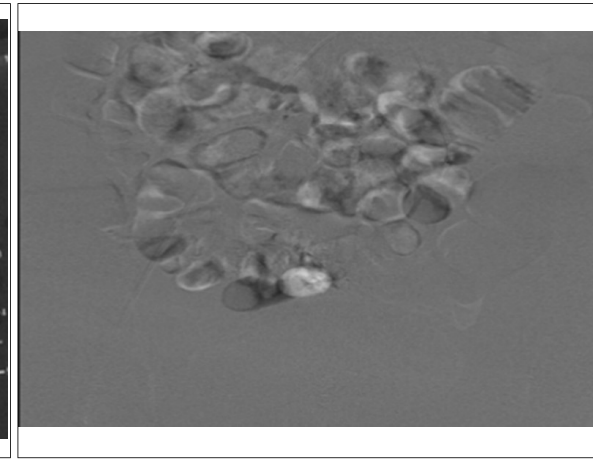

Figure 2 (a): ): Angiogram of uterine artery showed an arteriovenous malformation (AVM).

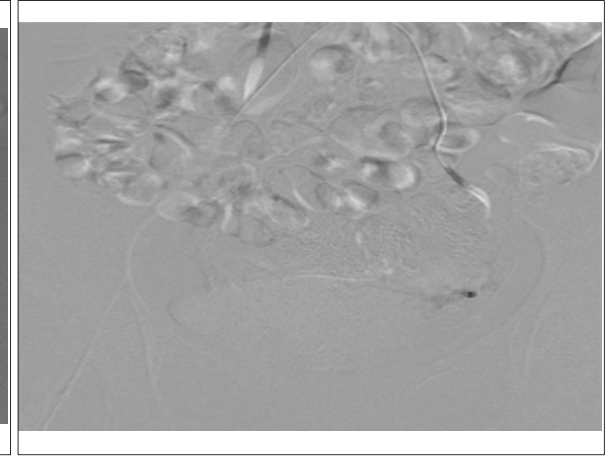

Figure 2 (b): Post-embolization showed complete embolization of the AVM.

\section{DISCUSSION}

In women of reproductive age group, the most common causes of abnormal uterine bleeding are complication related to pregnancy. Uterine AVM, although uncommon, should be considered in patients with unexplained uterine bleeding after abortion. Uterine AVM results in sudden and massive vaginal bleeding that may endanger life, suggestive of arterial hemorrhage, when the vessels are ruptured from iatrogenic sloughing of endometrium during dilation and curettage. ${ }^{3}$

Many imaging methods have been used to diagnose AVMs. These include ultrasound, computed tomography (CT), angiography and magnetic resonance imaging (MRI); although in recent practice, color Doppler ultrasonography is the modality of choice to diagnose AVM, as it increases the accuracy of ultrasound. ${ }^{5}$

Important differential diagnosis includes retained products of conception and gestational trophoblastic disease, because of the hypervascular appearance with turbulent flow. In such cases, the serum $\beta$ HCG levels can help in confirming the diagnosis. 1

Treatment of uterine AVM varies from expectant and medical management to surgical management. Medical management includes danazol or gonadotropin releasing hormone analogues in patients with mild hemorrhage. 6,7

The treatment of patients with AVM depends upon the patient age, size and site of lesion and desire to retain fertility. The patient can be offered intervention options from minimally invasive uterine artery embolization to definitive surgical hysterectomy. ${ }^{8}$

Angiographic arterial embolization has now-a-days become the preferred management, because it is minimally invasive and preserves fertility. It is considered in cases where women experience recurrent or severe bleeding and become hemodynamically unstable. 9 The advantages of arterial embolization include $\geq 95 \%$ success rate, lower complication rate and avoidance of surgical risks.3,10 The procedure-related side effects include low grade fever, infection or pelvic pain. The complications of uterine arterial embolization are negligible when performed by interventional radiologist. 3

In the current case report, the AVM was diagnosed by color Doppler scan and successfully managed with uterine artery embolization.

In conclusion, uterine AVMs are uncommon, lifethreatening clinical condition, which should be considered in patients with unexpected heavy and irregular vaginal bleeding after delivery or any surgical procedure involving the uterus.

\section{REFERENCES}

1. Aslan $H$, Acar KD, Ekiz A. Sonographic features and management option of uterine arterio-venous malformation. Six case reports. Med Ultrason 2015; 17:561-3.

2. Igbinedion $\mathrm{EB}, \mathrm{Kurlkarn} \mathrm{S}$. Uterine arterio-venous malformation: A review of current literatures. PJR 2013; 23:22-30.

3. Chan Y, Wang G, Xic F. Embolization of uterine arterio-venous malformation. Iran J Reprod Med 2013; 11:159-66.

4. Campus $P$, Levaillent JM, Teig B, Fernandez $H$. Uterine arteriovenous malformation involving the whole myometrium. Ultrasound Obstet Gynecol 2013; 41:715-7.

5. Krishnan V. Heavy vaginal bleedind, post termination of pregnancy: not always retained product of conception. Int $J$ Rep Contracept Obstet Gynecol 2014; 3:273-5.

6. Takeuchi K, Yamada T, Iwasa M, Mauro T. Successful medical treatment with danazol after failed embolization of uterine arteriovenous malformation. Obstet Gynecol 2003; 102:843-4.

7. Nonaka T, Yahata T, Kashima K, Tanak K. Resolution of uterine arteriovenous malformation: A case report of 2 cases and review of literature. J Minim Invasive Gynecol 2011; 18:812-9.

8. Bagg R, Verma P, Aggarwall N. Failed angiogenic embolization in uterine arteriovenous malformation: $A$ case report and review of literature. Amaedscape J Med 2008; 10:12.

9. Timmerman TD, Bosch T, Peeraer K, Debrouwere E, Schoubroeck D. Stockx L, et al. Vascular malformations in the uterus: ultrasonographic diagnosis and conservative management. Eur J Obstet Gynecol Reprod Biol 2000; 92:171-8.

10. Igbinedion EOB, Kurlkarnis $S$. Uterine arteriovenous malformation: A review of current literatures PJR 2013; 23: 22-30. 